- $81 \%$ of clinical dental technicians welcomed the prospect of statutory registration with the GDC, indicating that it would be likely to enhance their professional profile.

- $71 \%$ operated in organised business settings employing a number of other staff.

- Educational providers should be encouraged to initiate programmes of training to accommodate those who wish to pursue this career on a formal basis.

- Clinical dental technicians have the potential to make an impact on the provision of specific areas of oral care.

\title{
Activity and education of clinical dental technicians: a UK survey
}

\author{
M. K. Ross, ${ }^{1}$ R. J. Ibbetson ${ }^{2}$ and S. Turner ${ }^{3}$
}

Aims This survey aimed to determine the clinical activity of clinical dental technicians (CDTs) in the UK and to establish their employment status, views of statutory registration and need for further education. Until 2006, this practise was illegal in the UK.

Materials and methods A postal questionnaire was sent to 128 members of the Clinical Dental Technicians' Association (CDTA) who had agreed to participate in this study. Analysis was conducted using standard non-parametric statistical tests and quantitative techniques. Results A response rate of $54 \%$ was achieved. Qualifications in clinical dental technology from George Brown College, Toronto, Canada were held by $68 \%$, with $16 \%$ currently undergoing training and $16 \%$ neither qualified nor in training. The majority (90\%) owned a laboratory with $61 \%$ stating they had between one and four dental surgeries on site. CDTs with Canadian qualifications tended to provide a wider range of procedures, coupled with patient lists and recall systems, compared to those not so qualified. Eighty-one percent welcomed the prospect of statutory registration with $82 \%$ indicating that it would enhance their professional profile.

Conclusions This small but significant survey gives some insight of the work which has been undertaken by CDTs for many years, albeit illegally. With appropriate training and education, and consequent GDC registration, CDTs will be in a position to make a positive contribution to the clinical care of patients.

\section{INTRODUCTION}

The Nuffield Foundation Report of 1993, Education and training of personnel auxiliary to dentistry, aimed to describe what

\footnotetext{
Senior Lecturer, ${ }^{2}$ Professor of Dental Primary Care \& Director, ${ }^{3}$ Senior Researcher, Edinburgh Postgraduate Dental Institute, The University of Edinburgh, 4th Floor, Lauriston Building, Lauriston Place, Edinburgh, EH3 9HA

${ }^{*}$ Correspondence to: Mrs Margaret K. Ross

Email:margaret.k.ross@ed.ac.uk
}

\section{Online article number E22}

Refereed Paper - accepted 12 July 2007

DOI: $10.1038 /$ bdj.2007.965

${ }^{\circ}$ British Dental Journal 2007; 203: E22 a dental and oral health service should provide, and ways in which it could be delivered more cost-effectively by using additional auxiliaries who were trained to national standards. ${ }^{1}$

Many of the early proposals have, after much deliberation by various groups, been adopted by the General Dental Council. Dentistry is currently undergoing perhaps its most extensive reform and modernisation process, with the roles and responsibilities of non-dentists or dental care professionals (DCPs) progressing in line with Nuffield's suggestions. This is evident particularly in relation to dental hygienists and dually-qualified dental hygienist-therapists, whose clinical remit has increased substantially since 1996, and is likely to continue to do so as a result of the recently announced changes to the Dentist Act (1984). ${ }^{2}$

In contrast, the recommendations of the 1993 enquiry relating to clinical dental technicians (CDTs) are only now beginning to come to fruition. 2006 witnessed the establishment of formal education and subsequent registration for this previously unregistered, and until that time, illegal group of healthcare workers in the UK. Following registration, CDTs will be able to open their own practices and to construct and fit full dentures without referral or any other intervention by a dentist. Historically, the law has been much less restrictive in other countries. For example, in Canada, Australia, Denmark and the Netherlands, CDTs or denturists as they are also known, have been able to construct and fit dentures directly for patients for some time.

CDTs have existed in the UK for many years, with there being a tacit agreement that this constituted illegal practise. However, their activity has been largely ignored unless prosecution has been instigated. As a result of this illegal status, little is known about CDTs in the UK. A number of UK-based individuals have undertaken education in clinical dental technology via George Brown College, Toronto, Canada, where 90\% of the course is delivered via distance learning, although the clinical component has to be undertaken in Canada. Very recently, following a successful submission to the GDC, the Faculty of General Dental Practice (UK) of the Royal College of Surgeons 
of England has agreed to award the Diploma in Clinical Dental Technology to Diplomates of the Canadian College, following appropriate 'top-up' education and successful examination at one of their approved centres in the UK. This Diploma, once awarded, will allow clinical dental technicians to apply for statutory registration with the General Dental Council.

Recognition of the need for formal education of CDTs in the UK, and acknowledgement of the benefit of this group of DCPs in treatment provision, are reflected in the formulation of a curriculum detailed in the GDC document, Developing the dental team. ${ }^{3}$ The GDC stipulates that potential students must already hold a recognised qualification in dental technology. There are currently no existing training courses for qualified dental technicians to undertake the full programme of CDT education in the UK, although a number of centres are exploring this possibility at present.

The legalisation of this profession in the UK must be viewed as a positive step, as it is not in the public interest to have treatment provided by unregulated individuals with little or no formal training. Regulation by the GDC will protect the public, which is the prime concern of the Council, and statutory registration will raise the profile of the group to that of other health professionals, provide additional access to care and create further freedom of choice for patients.

The purpose of this investigation was to establish the current activity of clinical dental technicians in the UK and to assess their need for education. It follows previous research into the employment status and educational needs of dental hygienists, dental technicians and dental nurses by the same authors. ${ }^{4-6}$ The survey also hoped to provide a reference point on which future developments for CDTs could be based.

\section{MATERIALS AND METHODS}

Contact was established with the Clinical Dental Technicians' Association (CDTA) which agreed to facilitate access to its membership. The CDTA's initial invitation to take part was accepted by 128 of their 250 members. As the authors did not have any control of this primary contact, it was not known how many of the remaining 122 were ineligible for inclusion in the study due to non-UK residence, retirement or other reasons. It was therefore not possible to calculate an overall response rate. Of the 128 CDTs who agreed to participate, 69 UK-based CDTs returned completed questionnaires when the survey was conducted in 2006, eliciting a response rate of $54 \%$. How representative respondents are of the wider group of CDTs is unclear, therefore caution is recommended when interpreting results.

Quantitative and qualitative data were collected and an open-ended section was included for general comments. In order to investigate how qualifications related to service provision, a seven-point service scale was constructed to reflect provision of full, partial and overdentures, other prostheses, other treatments, patient list availability and a patient recall system.

\section{RESULTS}

\section{Background information}

a) Sex

The vast majority of respondents were male $(96 \% ; n=66)$ with only $3(4 \%)$ being female.
Table 1 Location of employment of respondents

\begin{tabular}{l|l}
\hline Area & Number of respondents \\
\hline London and the South East & 30 \\
\hline South West & 13 \\
\hline Midlands & 7 \\
\hline North of England & 12 \\
\hline West of Scotland & 2 \\
\hline East of Scotland & 1 \\
\hline Northern Ireland & 1 \\
\hline Unspecified location & 3 \\
\hline
\end{tabular}

Table 2 Types of clinical services provided by respondents

\begin{tabular}{l|l}
\hline Treatment type & Number of respondents \\
\hline Full dentures only & 1 \\
\hline Full and partial dentures & 8 \\
\hline Full, partial and overdentures & 15 \\
\hline $\begin{array}{l}\text { Full, partial, overdentures and } \\
\text { other prostheses* }\end{array}$ & 36 \\
\hline Full and partial dentures, other prostheses* & 7 \\
\hline $\begin{array}{l}\text { *Other prostheses: gum/bite/mouthguards, anti-snoring splints, implants, cobalt-chromium } \\
\text { dentures, bleaching trays. }\end{array}$ &
\end{tabular}

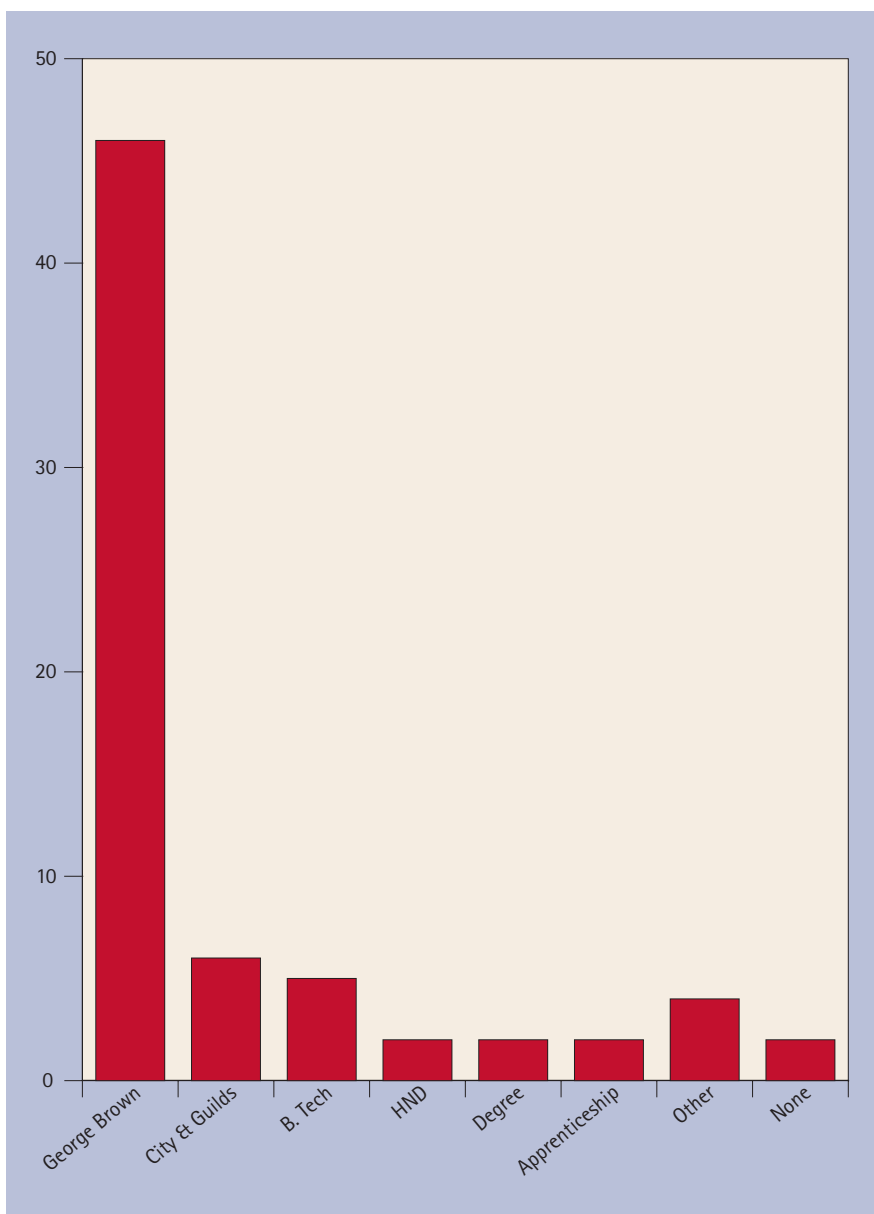

Fig. 1 Respondents' qualifications 


\section{b) Age}

The majority of subjects $(61 \% ; n=42)$ reported being aged 35-50 with 10\% ( $\mathrm{n}=7$ ) being under 35 years old and 29\% (n $=20$ ) of respondents aged 50 or over, including two subjects who were still working after the traditional retirement age of 65 years of age.

\section{c) Location of respondents}

The geographical location of respondents is illustrated in Table 1.

\section{d) Qualifications}

The respondents' qualifications are shown in Figure 1.

This paper defines only those who had undertaken the George Brown College, Toronto, Canada course as holding a qualification in clinical dental technology. Therefore, 46 (67\%) were considered qualified. A further 11 (16\%) stated they were currently in training with George Brown College and 11 (16\%) reported being neither qualified nor in training. Three individuals stated they had undertaken the Canadian course, although they did not consider themselves qualified.

\section{e) Years since qualification and length of training}

The duration of training ranged from 2-9 years, giving a mean of 3.5 years. Those who held the Canadian qualification $(n=45)$ reported having been in employment for a mean of 10.3 years, compared to 5.8 years for those who were not. This difference was statistically significant $(t=2.31, d f=68, p=0.05)$.

\section{f) Funding}

Only five respondents claimed they had received funding during training, although two of these were personal loans. Two quoted the Department of Trade and Industry and the European Union as providing support and the remaining subject did not specify the source of funding.

\section{g) Other qualifications (outwith dental technology)}

Seven CDTs held additional qualifications. These were: dental radiography (2); unspecified City \& Guilds (1); certificate in education (1); first aid (1); business management (1); unspecified qualification (1).

\section{Place of work}

a) Status in laboratory and time in employment

Of the respondents, $90 \%(\mathrm{n}=60)$ stated they were the laboratory owner, with only $7 \%(n=5)$ claiming they were employees. Two subjects reported they were laboratory owners although they did not work in the premises, and two did not respond. The majority of respondents $(n=66 ; 96 \%$ ) reported being in full-time employment, on average for a period of 8.65 years ( $\mathrm{sd}=8.12$ years, range $0-31)$.

\section{b) Other employees in laboratory}

Thirty-three percent $(n=23)$ of respondents stated they did not have any other CDTs working in the laboratory, 51\% ( $\mathrm{n}=$ 35) reported one other individual in employment and 16\% ( $\mathrm{n}=$ 11) stated that two or more CDTs worked in the same establishment. When asked about those employed purely as dental technicians, 39\% ( $\mathrm{n}=26)$ stated that none were employed, $24 \%$ ( $\mathrm{n}=16)$ reported one, $28 \%(\mathrm{n}=19)$ between 2 and 8 , and $9 \%$ $(n=6)$ stated they had 10 or more technicians in employment (missing: 2). Only 15\% ( $\mathrm{n}=10)$ reported having any dental nurses in employment, with just one laboratory having more than one dental nurse on site. Seventy-one percent $(n=47)$ reported that other staff were employed within the laboratory as follows: secretarial/administrative staff (20 CDTs); drivers (19); receptionists (18); laboratory staff/trainees/assistants (7); cleaners (4).

\section{c) Dental surgery in laboratory}

Subjects were asked whether they had a dental surgery located within their laboratory. Of those who responded (67), 41 (61\%) reported they had this facility. In total, 30 CDTs had one surgery, five had two, two had three and one CDT claimed to have four surgeries available within their laboratory. Three CDTs did not comment on surgery availability.

\section{Patient services}

a) Patient lists and recall systems

In terms of a patient list being kept, 65\% $(n=45)$ reported they did so and, of these, 24 (53\%) operated a recall system.

b) Clinical services

Table 2 indicates the types of clinical services provided for patients.

A total of $24 \%(n=16)$ stated they offered a number of additional treatments including relines, repairs, technical advice, oral hygiene advice and bleaching treatments. A service measure was constructed by summing provision of each of the above services, plus running a patient list and recall system (mean: 4.7 , sd $=1.30$, range $1-7$ ). Those CDTs holding the George Brown College qualification gained a higher score (mean 4.19, $\mathrm{sd}=1.29, \mathrm{n}=21$ ). This difference was statistically significant $(t=2.33, \mathrm{df}=65, \mathrm{p}=0.05)$.

\section{c) Referrals from GDPs and fee structures}

A total of $85 \%(n=58)$ of CDTs accepted referrals from GDPs. In terms of fee structures, $91 \%(n=60)$ reported they charged privately, whilst $8 \%(n=5)$ stated they operated a mix of private and NHS fee structures, with only one stating only NHSbased fees were charged.

\section{Continuing professional development \\ a) Frequency of CPD and funding}

Asked about their frequency of attendance on courses and educational meetings, 51\% $(n=35)$ reported attending one to two events in the preceding 12 months, 38\% $(n=26)$ reported attendance at more than two such events in the same time period, 4\% ( $\mathrm{n}=3)$ had attended a course in the last two years and 5\% $(n=4)$ had not done so for over two years. Only two subjects reported having received any financial assistance to undertake CPD.

\section{b) Access and availability of CPD}

The problem of access to CPD was reported by $38 \%(n=24)$ subjects and $81 \%(n=55)$ stated that there were insufficient CPD events available. Of these, 21 respondents referred to a scarcity of suitable UK-based courses, 11 cited inappropriate content and 10 attributed the lack of CPD to the illegal basis of denturist practice. The remaining 13 subjects made no comment. 


\begin{tabular}{l|l|}
\hline \multicolumn{2}{|l}{ Table 3 Respondents' suggestions for future CPD subjects } \\
\hline Subject & Number of respondents \\
\hline $\begin{array}{l}\text { Clinical training including anatomy, } \\
\text { pathology and clinical skills }\end{array}$ & 22 \\
\hline Any CDT-related subjects & 8 \\
\hline Practice administration and management & 5 \\
\hline Health and safety and patient care & 4 \\
\hline
\end{tabular}

\section{c) Suggested subjects for future CPD}

A total of $56 \%(n=39)$ made suggestions regarding the content of future courses. Details are given in Table 3.

\section{d) Perceived need for CPD}

Despite their widespread perception of need for training, 74\% ( $n=49)$ said they felt up to date with education.

\section{The future}

a) Statutory registration with the General Dental Council

The majority of respondents $(82 \%, \mathrm{n}=53)$ felt that registration would enhance their professional profile, whilst a similar proportion $(81 \%, n=52)$ stated that they welcomed the proposed move to registration. However, 10 CDTs stated they had reservations about becoming statutorily registered. Some of the more significant comments are listed below:

- 'The GDC do not have my interest at heart'

- 'Would rather be registered with the Royal College of Surgeons! GDC is run by dentists for dentists'

- 'A new independent registration should have been set up, free of the old prejudice'

- 'I did until recently, but new rules governing [the provision of] dentures are likely to close the laboratory clinic'

- 'Still apprehensive about this.'

\section{b) Expansion of role}

In relation to the expansion of the role of the CDT, $84 \%$ ( $\mathrm{n}=$ 54) thought that this was probable in the future. A number of suggestions of further clinical duties was offered, the more popular of which are listed below:

- Tooth whitening

- Preparation of teeth for denture rests

- Fitting crowns and veneers

- Construction and fitting of partial dentures

- Implant-retained work

- Small fillings.

\section{c) Future employment}

The majority of respondents $(93 \%, \mathrm{n}=62)$ stated that they intended to remain in the profession of clinical dental technology.

\section{d) General comments about clinical dental technology}

- 'There should be a transitional period for any qualified technician that has successfully provided dentures to the public for over seven years and can prove competent in their field of work. 42 years as a qualified technician and over 15 years as a denturist must count for something!'

- 'My eyes have been opened since completing my course and qualifying [via George Brown College, Canada]. I realised that dental technicians did not have anywhere near enough knowledge to work in the mouth and provide well-fitting healthy dentures. We also have acquired enough medical training to act as another safeguard against oral disease referring patients to other professionals. When we see the patient and make the dentures it is much easier to get good results'

- 'I would like to register as soon as possible. I would like confirmation that all unregistered technicians doing clinical work are going to be stopped until training has been completed - to give an equal playing field'

- 'Registration and regulation by the GDC is essential together with periodic inspection to ensure patient protection and satisfaction'

- 'For many years patients, government and the profession within dentistry have accepted the superior abilities of CDTs, all except dental surgeons. With a few exceptions, that prejudice will still remain beyond my retirement. I have a dream that one day, all dental professionals will be equal'

- 'A high proportion of patients I see come as a result of poor clinical work carried out by a dentist'

- 'New rules governing the provision of partial dentures will be unworkable. In the event that I refer all partially dentate clients to a dentist first, am I really expected to believe that they will be referred back to me, or if so, with an appropriate design? I am confident that with dentists' lists so full, half of them I refer will actually just go and see other technicians without appropriate training and qualifications'

- 'Most of my work is done with the dentists in the practice I am attached to. I can fit a denture in minutes - the younger ones [dentists] tend to find it difficult. Some young dentists come to the practice not knowing how to take impressions or take bites'

- 'I feel we are in fact better qualified than many dentists to provide prosthetic appliances.'

\section{DISCUSSION}

The emergence of legally qualified clinical dental technicians in the UK heralds the arrival of a group of DCPs who will be able to contribute directly to patient care, thus fulfilling one of the visions of the Nuffield Enquiry of 1993. This study has been able to report directly from a group of dental care professionals whose activities, experience and views have hitherto been largely unknown. It should be borne in mind that this investigation was relatively small in size and it is perhaps unclear how representative it may be of the wider profession. There do not appear to be any independent estimates of the number of CDTs working in the UK, however, at the time of this study, the CDTA estimated that there were between 500-1,000 CDTs in employment. For the time being, the exact number of technicians assuming a clinical role is unlikely to be precise. Clearly, this was a difficult survey to conduct in light of the fact that, at that time, potential respondents were aware they would be admitting to work of an illegal nature. In this context, the level of response is felt to be satisfactory.

Anecdotally, there has been a degree of opposition to the training and subsequent acceptance of CDTs by others in the dental profession, the reasons for which are unclear. Several theories have been suggested, for example, their training 
would be inadequate, they would detract from the service provided by a dentist and their role within the team was vague. In our survey, $67 \%$ had undertaken as much training as they could access via George Brown College, Toronto. This training programme was inspected and assessed by visitors appointed by the Faculty of General Dental Practice (UK) of the Royal College of Surgeons of England and the curriculum and training were compared to the curriculum set out for CDT training by the GDC. A number of gaps were discovered and, as a result of this, a 'top-up' course was developed, allowing graduates to sit a UK examination and if successful, to apply for statutory registration. The evidence from this survey suggests that those who had undertaken a recognised qualification in clinical dental technology provided a more comprehensive and organised clinical service. There is no requirement to be a qualified dental technician prior to embarking on clinical dental technician training in Canada, which is contrary to the situation in the UK. The total number of weeks which the GDC suggests as guidance for CDT education is not less than 90 weeks, which is in addition to time taken to acquire a qualification in dental technology. In the UK, GDC guidance suggests a minimum period of 120 weeks to train as a dental technician. Accreditation of prior learning may reduce an individual's qualifying period.

The prospect of statutory registration was welcomed by $81 \%$ of respondents. However, this will not be an option for those $23 \%(\mathrm{n}=16)$ of CDTs who were neither qualified, nor in training at the time of investigation. These individuals will have to undertake a full training programme, but whether they will do so to facilitate legal practice is questionable. They would, of course, still be able to work as a dental technician (if registered) during any additional period of clinical training, thus still being in a position to generate an income. However, it may well be the case that they will continue to function as before.

Two respondents reported that the Department of Trade and Industry contributed to the funding of their education in Canada. This is clearly an anomalous situation given that this Department would be just as likely to prosecute dentists for carrying out bleaching procedures, for example, whilst simultaneously giving financial support to illegal training and practice!

Once registered, qualified CDTs will be in a position to hold professional indemnity, a facility which will not be available to the unqualified, illegally practising individual. This is a positive step which will increase patient protection and bring the profession in line with other DCP groups. However, it has not acted as a deterrent to those working illegally in the past and it will be interesting to see how this particular 'lack of insurance' issue develops.

From a global perspective, the UK has been reluctant to embrace the work of the CDT when compared to their successful activity in other countries. Changing demographics in this country means that people are living longer, with many retaining their teeth into older age. For the edentulous in this group, access to the provision of dentures is likely to become increasingly difficult and so to extend the workforce with CDTs will broaden the availability of this service. However, it would seem that NHS fee structures would have to be made more attractive to entice people into this service, given that this investigation demonstrated that 91\% of CDTs operated totally private fee structures, many in apparently wellexecuted business settings, as evidenced by the $71 \%$ who employed other staff.

Fifty-four percent of respondents admitted to other clinical practises including the provision of partial dentures, which is currently illegal. It is questionable if this practise will cease with registration, but perhaps this might be an 'extended duty' in any future revision of the CDT curriculum. It is an interesting observation that this previously illegal group will be the only dental care professionals able to treat patients directly and undertake diagnosis and treatment planning, without requiring a referral from a dentist. Dental hygienists and hygienist-therapists have significantly more patient contact hours during their basic education than those involved in CDT education and, as the law stands at present, are not permitted to undertake either diagnosis or treatment planning. It is unclear why there should be such a marked inconsistency in the governance of the clinical practice of those involved directly in intra-oral care.

Following qualification and subsequent registration, clinical dental technicians will have the potential to make an impact on the provision of specific areas of dental care. However, it is likely that not all CDTs currently practising illegally will pursue formal education, so it remains to be seen what the future will hold for them. For those who wish to practise openly and to ensure that this profession sheds its illegal and somewhat 'underground' profile, educational providers should be encouraged to initiate programmes as per the requirements of the GDC curricula frameworks and financial support should be made available to expedite this development.

We are indebted to the Clinical Dental Technicians' Association for facilitating access to their members in order to conduct this survey, and to the respondents for their participation.

1. The Nuffield Foundation. Education and training of personnel auxiliary to dentistry. London: The Nuffield Foundation, 1993.

2. The Dentists Act 1984 (Amendment) Order 2005.

3. General Dental Council. Developing the dental team. Curricula frameworks for registrable qualifications for professionals complementary to dentisty (PCDs). London: General Dental Council, 2004.

4. Ross M K, Ibbetson R J, Rennie J S. Educational needs and employment status of Scottish dental hygienists. Br Dent J 2005; 198: 105-109.

5. Ross M K, lbbetson R J. Educational needs and employment status of Scottish dental technicians. Br Dent J 2005; 199: 97-101.

6. Ross M K, lbbetson R J. Educational needs and employment status of Scottish dental nurses. Br Dent J 2006; 201: 661-666. 